\title{
O PATRIMÔNIO CULTURAL IMATERIAL DE ALAGOAS COMO ESTRATÉGIA DE DESENVOLVIMENTO TERRITORIAL
}

\author{
Verônica Nascimento Brito Antunes ${ }^{1}$ \\ Jacilene dos Santos Silva ${ }^{2}$ \\ Mônica Nascimento Brito ${ }^{3}$
}

Resumo: O presente artigo pretende examinar a diversidade do patrimônio cultural imaterial de Alagoas, enquanto recurso para promoção do desenvolvimento territorial. Para tanto, objetiva-se fazer um levantamento dos registros de patrimônios imateriais do estado, bem como possíveis indicações geográficas, e verificar o potencial de tais referências culturais se tornarem fontes de dinamismo. A pesquisa tem caráter qualitativo, descritivo e analítico e empregou os instrumentos de revisão bibliográfica, pesquisa documental e entrevista individual. Verificou-se que, a despeito do reconhecimento da riqueza e diversidade do patrimônio cultural alagoano, muito ainda precisa ser feito no sentido de valorização e transformação desses recursos em ativos a serviço do desenvolvimento.

Palavras-chave: Patrimônio cultural imaterial de Alagoas. Diversidade cultural. Indicações geográficas. Desenvolvimento territorial.

\section{CULTURAL HERITAGE OF ALAGOAS AS A TERRITORIAL DEVELOPMENT STRATEGY}

\begin{abstract}
The present article intends to examine the diversity of intangible cultural heritage of Alagoas, as a resource for the promotion of territorial development. In order to do so, the objective is to make a survey of the records of intangible heritage of the state, as well as possible geographical indications and verify the potential of such cultural references become sources of dynamism. The research is qualitative, descriptive and analytical and employs the instruments of bibliographic review, documentary research and individual interview. It was verified that, despite the recognition of the richness and diversity of the cultural heritage of Alagoas, much still needs to be done in the sense of valuing and transforming these resources into assets for development.
\end{abstract}

Keywords: Cultural heritage of Alagoas. Cultural diversity. Geographical indications. Territorial development.

\section{EL PATRIMONIO CULTURAL IMATERIAL DE ALAGOAS COMO ESTRATEGIA DE DESARROLLO TERRITORIAL}

Resumen: El presente artículo pretende examinar la diversidad del patrimonio cultural inmaterial de alagoas, como recurso para la promoción del desarrollo territorial. Para ello, se pretende hacer un levantamiento de los registros de patrimonios inmateriales del estado, así

\footnotetext{
1 Doutora em Políticas Públicas, Estratégias e Desenvolvimento pelo IE/UFRJ. Professora adjunta da Universidade Federal de Alagoas, Brasil. Email: veronicanbantunes@ gmail.com

${ }^{2}$ Mestre em Economia Aplicada pela Universidade Federal de Alagoas. Email: ja_cilene@ @otmail.com

3 Mestranda vinculada ao Programa de Pós-Graduação em Educação Agrícola da UFRRJ. Email: monicauenf@yahoo.com.br
} 
como posibles indicaciones geográficas y verificar el potencial de tales referencias culturales convertirse en fuentes de dinamismo. La investigación tiene carácter cualitativo, descriptivo y analítico y emplea los instrumentos de revisión bibliográfica, investigación documental y entrevista individual. Se verificó que, a pesar del reconocimiento de la riqueza y diversidad del patrimonio cultural alagoano, mucho aún necesita ser hecho en el sentido de valorización y transformación de esos recursos en activos al servicio del desarrollo.

Palabras clave: Patrimonio cultural inmaterial de Alagoas. Diversidad cultural. Indicaciones geográficas. Desarrollo territorial.

\section{Introdução}

Ao refletir sobre os desafios do desenvolvimento, Pecqueur (2000) confirma a necessidade de pôr em evidência a dinâmica que valoriza a eficácia das relações não exclusivamente mercantis entre os homens, de modo a valorizar as riquezas das quais dispõem, ao mesmo tempo em que propõe o reforço da perspectiva territorial.

A perspectiva territorial do desenvolvimento ressalta as particularidades históricas, institucionais e culturais que inviabilizam o desenho de um modelo único para trajetórias de desenvolvimento. Desta forma, as relações de poder, os atores locais, a hierarquia, as instituições, e especialmente as manifestações culturais que compõem os territórios, ampliam o debate sobre a construção de um projeto de desenvolvimento territorial com base no "sentido de pertencimento" que combinem ações em múltiplas escalas.

Entende-se que a cultura envolve um complexo de saberes e expressões capazes de proporcionar, entre outras coisas, a expansão das capacidades e das bases produtivas de uma sociedade. Isto vem se estabelecendo em virtude das várias discussões a respeito da posição antes ocupada pela cultura nas diversas localidades, além de sua expansão na área econômica e política. Ressalte-se que a busca por inovações culturais, ao passo em que auxilia na compreensão do diferencial, tem estimulado a valorização dos recursos locais e a retomada de suas tradições.

Neste sentido, o reconhecimento da diversidade cultural de um território é um elemento chave para repensar o progresso sob uma ótica que vai além do crescimento econômico e sim privilegia os diferentes recursos (materiais e simbólicos) como fontes de dinâmicas territoriais. Especialmente o patrimônio cultural imaterial, entendido como saberes, ofícios e manifestações criados e recriados por grupos sociais, revelam a interação com a natureza e com a história, com vistas a preservação da identidade e continuidade da 
diversidade e evolução humana. Por tais motivos, essa pesquisa pretende discutir esses aspectos da cultural imaterial como estratégias de desenvolvimento.

É fato que as regiões brasileiras apresentam distinções em múltiplos aspectos tais como sociais, econômicos, climáticos e culturais. Neste último aspecto, a variedade de influências étnicas, sobretudo européia, indígena, africana, dentre outras, revela a diversidade cultural apresentada no País.

No que tange o estado de Alagoas verificou-se um rico patrimônio cultural imaterial proveniente dessas vertentes étnicas. Um dos principais destaques do estado é o artesanato (trabalhos em rendas e bordados, palha, madeira e cerâmica) no qual alguns municípios possuem núcleos de produção, sendo a tecelagem o gênero artesanal de maior destaque transmitido por gerações. Na sua capital, Maceió, e no município de Marechal Deodoro encontra-se o Filé (renda alagoana); em Porto Real do Colégio, Traipú e São Brás está o Redendê e o Ponto de Cruz; já no município de Pão de Açúcar está a Boa-noite; e em São Sebastião as Rendas de Bilro. A culinária também é um dos pontos fortes em Alagoas. Existe uma ampla variedade de peixes e frutos do mar decorrente da riqueza das lagoas costeiras e de seu amplo litoral.

Outro destaque do estado de Alagoas é o folclore, tendo suas raízes vindas dos negros, brancos e índios. Durante todo o ano ocorrem as manifestações folclóricas conforme o período das festividades, dentre as mais conhecidas, no período natalino, estão o Pastoril, Guerreiro, Taieira, Baianas, Reisado, Cavalhada, Marujada e Presépio. O Mané do Rosário e Bandos dos Carnavalescos, Cambindas, Negras da Costa, Samba do Matuto, Coco Alagoano, entre outros são destaques das festas religiosas. A Quadrilha, o Coco de Roda, a Banda de Pífano, os violeiros e repentistas são os maiores destaques cantados e dançados.

O presente artigo pretende examinar a diversidade do patrimônio cultural imaterial de Alagoas, enquanto recurso de promoção do progresso. Para tanto, objetiva-se levantar os registros de bens imateriais do estado, bem como possíveis indicações geográficas e verificar o potencial de tais referências culturais se transformarem em ativos a serviço do desenvolvimento territorial.

A pesquisa tem caráter qualitativo, descritivo, analítico e empregou os instrumentos de revisão bibliográfica, pesquisa documental e entrevista individual. Especificamente, em termos metodológicos, além da construção dos elementos teóricos, foram realizados os seguintes processos: análise do escopo (conteúdo) de Decreto Federal e Lei Estadual que 
dispõem sobre os registros de patrimônio cultural imaterial no Brasil e em Alagoas, respectivamente; consultas à Secretaria Estadual de Cultura (SECULT) e Instituto do Patrimônio Histórico e Artístico Nacional (Iphan) para verificação das referências aos bens imateriais e indicações geográficas; entrevistas de representantes da SECULT para o levantamento de informações sobre o andamento dos registros e compreensão de sua interação com o Iphan.

O trabalho está estruturado em quatro seções além desta introdução. A seguir, discutese o enfoque territorial na busca do desenvolvimento para construção do referencial teórico que ilumina a pesquisa. Na terceira seção, foram expostos alguns aspectos do patrimônio cultural imaterial de Alagoas, tais como a legislação específica, sua diversidade e localização. Na quarta seção, apresenta-se uma reflexão acerca da capacidade dos bens imateriais e das indicações geográficas se transformarem em ativos do desenvolvimento, e na sequência foram apresentadas as considerações finais.

\section{A perspectiva territorial do desenvolvimento}

Uma das primeiras formas de conceituação de território surgiu no campo da geografia, onde a idéia de relação de poder aparece, direta ou indiretamente, na caracterização do território. Dentre as significativas contribuições está a de Raffestin (1993), que procura diferenciar o conceito de espaço ao de território.

Considera-se que o conceito de espaço é relacionado ao patrimônio natural existente numa região definida, por outro lado, no conceito de território se incorporaria a apropriação do espaço pela ação social de diferentes atores. Em outras palavras, o conceito de território incorpora o jogo de poder entre os atores que atuam num espaço, sendo caracterizado como resultado de uma ação social que, de forma concreta e abstrata, se apropria de um espaço (tanto físico como simbolicamente), por isso denominado um processo de construção social.

Milton Santos (1994) aponta que entre as escalas global, nacional e local, permeia o "território usado"4 e que o mesmo é um conceito indispensável para compreensão do mundo. O autor também destaca uma inovação do funcionamento do território, através de horizontalidades (ou seja, lugares vizinhos reunidos por uma continuidade territorial) e verticalidades (formadas por pontos distantes uns dos outros, ligados por todas as formas e processos sociais).

\footnotetext{
${ }^{4}$ Ver Santos, Milton. Território, Globalização e Fragmentação. São Paulo: Hucitec, 1994.
} 
Já Pecqueur (2000) considera importante a diferenciação entre dois tipos de territórios. O primeiro deles seria aquele estabelecido por decisão político-administrativa, num processo “top-down” de decisão, cujos interesses, normalmente, são o estabelecimento de políticas de desenvolvimento da região pré-definida. Nesse caso, o território seria chamado de "território dado", espaço-lugar, que resulta como produtos das políticas de organização do território.

Outro tipo de território, o construído, ou espaço-território, que, segundo o autor, é formado a partir de "um encontro de atores sociais, em um espaço geográfico dado, que procura identificar e resolver um problema comum".

Segundo Abramovay (1998), “um território representa uma trama de relações com raízes históricas, configurações políticas e identidades que desempenham um papel ainda pouco conhecido pelo próprio desenvolvimento econômico".

Ao discutir a forma pela qual a noção de território favorece a análise das regiões rurais, o autor aponta para interessantes possibilidades do enfoque territorial: propõe que se abandone um horizonte estritamente territorial; favorece a diferenciação entre crescimento econômico e o processo de desenvolvimento, na medida em que os fenômenos sociais passam a ser multidimensionais exigindo análises institucionais; viabiliza o estudo empírico dos atores e de suas organizações, dos processos de cooperação entre os municípios e o estudo dos mecanismos de governança pública; o território coloca ênfase na maneira como uma sociedade utiliza os recursos de que dispõe em sua organização produtiva e, portanto, na relação entre sistemas sociais e ecológicos (FOLKE; BERKES,1998).

Territórios são resultados da maneira como as sociedades se organizam para usar os sistemas naturais em que se apóia sua reprodução, o que abre um interessante campo de cooperação entre ciências sociais e naturais no conhecimento desta relação[...] (ABRAMOVAY, 2004).

Ao refletir sobre os desafios do desenvolvimento, Pecqueur (2000) confirma a necessidade de pôr em evidência a dinâmica que valoriza a eficácia das relações não exclusivamente mercantis entre os homens, para valorizar as riquezas das quais dispõem, ao mesmo tempo em que propõe o reforço da perspectiva territorial. Nas palavras do autor:

"O desenvolvimento territorial designa todo processo de mobilização dos atores que leve à elaboração de uma estratégia de adaptação aos limites externos, na base de uma identificação coletiva com uma cultura e um território.” (PECQUEUR, 2005, p. 12).

O Quadro 1 ilustra o processo de transição da concepção de um desenvolvimento local para o desenvolvimento territorial. 


\section{Quadro 1 - A transição da concepção de desenvolvimento local para desenvolvimento territorial}

\begin{tabular}{|c|c|c|c|c|c|}
\hline & $\begin{array}{c}\text { Desenvolvimento } \\
\text { local }\end{array}$ & & & & $\begin{array}{c}\text { Desenvolvimento } \\
\text { territorial }\end{array}$ \\
\hline $\begin{array}{c}\text { Território } \\
\text { (nível espacial) }\end{array}$ & $\begin{array}{l}\text { Identidade } \\
\text { (local) }\end{array}$ & $\rightarrow$ & $\begin{array}{l}\text { Identidades } \\
\text { múltiplas }\end{array}$ & $\rightarrow$ & $\begin{array}{c}\text { Arena de } \\
\text { negociação } \\
\text { (multi-escalar) }\end{array}$ \\
\hline $\begin{array}{c}\text { Atores } \\
\text { (Institucionalidade) }\end{array}$ & $\begin{array}{c}\text { Parceria } \\
\text { público/privado } \\
(\mathrm{GAL})\end{array}$ & & $\rightarrow$ & & $\begin{array}{c}\text { Partes } \\
\text { interessadas } \\
\text { (Institucionalidade } \\
\text { complexa) }\end{array}$ \\
\hline Objetivos & $\begin{array}{l}\text { Crescimento } \\
\text { econômico }\end{array}$ & $\rightarrow$ & $\begin{array}{l}\text { Outros } \\
\text { objetivos }\end{array}$ & $\rightarrow$ & Múltiplos objetivos \\
\hline
\end{tabular}

Fonte: Extraído de Ferreira, 2009.

Em definição podem ser extraídas algumas conclusões: em primeiro lugar, essa perspectiva de desenvolvimento não pode ser firmada por decreto, tendo em vista que é construída ao longo tempo pelos atores; em segundo lugar, sendo um processo que responde aos reflexos da globalização, o desenvolvimento territorial consiste em uma estratégia de adaptação dos atores com intuito de reorganizar a economia local diante da crescente concorrência internacional; por fim, a dinâmica de territorialização fundamenta-se no princípio da especificação dos ativos, ou seja, o reconhecimento dos recursos que caracterizam o território e o diferencia dos demais.

Cabe destacar pelo menos duas possibilidades de construção e uso do território pelos atores sociais - uma ligada à ação coletiva dos atores locais e outra ligada à territorialização das políticas públicas (BONNAL, CAZELLA, DELGADO, 2012).

No que diz respeito a ação coletiva, a partir de uma representação compartilhada sobre a realidade, os atores identificam os limites do território, geralmente por agregação de unidades administrativas (municípios) ou sociais (sindicatos, organizações de agricultores, comunidades etc.) e constroem uma estratégia de ação. Trata-se nitidamente de um processo de construção social direcionado, no sentido de que a finalidade da ação é construir um projeto coletivo para o benefício de atores do território. Em consonância com a segunda possibilidade, o centro estratégico de ação se ancora em níveis mais abrangentes (estadual ou nacional). Nesta lógica, o território é identificado principalmente com referência ao zoneamento de determinado problema ou carência da sociedade. O desafio para o poder 
público é o de definir as modalidades de ação mais apropriadas para a resolução desse problema ou carência, levando em conta as especificidades locais.

Pecquer (2005) indica que o sistema territorial de atores pode adotar formas distintas de organização produtiva tais como distritos industriais, cluster, arranjos produtivos locais, mantendo como traços característicos ser construído pelos atores num processo dinâmico ao longo do tempo, não se limitando a otimização da dotação de fatores presentes no espaço. "Em outros termos, a dinâmica de desenvolvimento territorial visa revelar recursos inéditos, e é nisto que constitui uma inovação"

Ao analisar um conjunto de políticas e programas de desenvolvimento territorial existentes no Brasil, Favareto (2009) comenta:

\begin{abstract}
Embora o discurso sobre desenvolvimento territorial tenha entrado definitivamente para o discurso acadêmico e governamental na presente década, até o momento trata-se de uma incorporação 'por adição' dos novos temas, sem a devida mudança institucional capaz de sustentar a inovação que ela deveria significar.
\end{abstract}

Neste contexto, podemos interpretar por mudanças institucionais dois componentes da abordagem territorial: ações de caráter intersetorial e abrangência geográfica que extrapole o âmbito comunitário ou municipal. Segundo Favareto (2009) "inexiste no Brasil, em âmbito nacional, uma política pública que contemple ações intersetoriais e intermunicipais, tal como prevê a abordagem territorial do desenvolvimento".

Segundo Vieira (2009), ao longo dos anos de 1980 e 1990, emerge uma série de estudos relacionados as experiências de desenvolvimento local e desenvolvimento territorial em diferentes contextos nacionais que contribuíram para noção sistêmica de endogeneidade.

Frente as novas políticas territoriais rurais promovidas pelo Ministério do Desenvolvimento Agrário (MDA), Cerdan et al. (2009) apontam que as formas de aprendizagem e de coordenação territoriais entre atores sociais determinam a eficiência dos sistemas produtivos locais e a ativação de recursos específicos. Assim, as novas políticas públicas territoriais são oportunidades potenciais para fortalecer ou influenciar novas formas de governança.

\title{
Patrimônio imaterial de Alagoas: institucionalidade, diversidade e localização
}

No que diz respeito a legislação que define, resguarda, bem como traça as diretrizes para o registro do patrimônio cultural imaterial, foram analisados os seguintes aparatos

\footnotetext{
${ }^{5}$ Ibid, p. 12.
} 
institucionais: o Artigo 216 da Constituição Federal Brasileira (CFB), Decreto Federal no 3.55.1/2000 e Lei estadual $\mathrm{N}^{\circ} 7.285 / 11$.

A CFB/1988, Art. 216 define que patrimônio cultural brasileiro são: “bens de natureza material e imaterial, tomados individualmente ou em conjunto, portadores de referência à identidade, à ação, à memória dos diferentes grupos formadores da sociedade brasileira, nos quais se incluem." O referido artigo da CF presume ainda o reconhecimento dos bens culturais imateriais como patrimônio a ser salvaguardado pelo Estado em conjunto com a sociedade.

Em 04 de agosto de 2000, o governo brasileiro promulgou o Decreto $\mathrm{n}^{\mathrm{o}} 3.551$ que instituiu o Registro de Bens Culturais de Natureza Imaterial e criou o Programa Nacional do Patrimônio Imaterial (PNPI), sob a supervisão do Instituto do Patrimônio Histórico e Artístico Nacional (Iphan).

De acordo com o Iphan, os patrimônios registrados como bens culturais imateriais são caracterizados pelas práticas, representações e domínio da vida social tomados por pessoas e grupos sociais como elementos significativos de sua identificação, sendo esses transmitidos e recriados por grupos e comunidades de acordo com o âmbito, sua relação com a natureza e sua história. As formas tradicionais de expressão são classificadas, por serem importantes formadoras da memória e da identidade dos grupos sociais, assim, corroborando para a promoção do respeito à diversidade cultural.

Neste contexto, e conforme o Decreto $n^{\circ} 3.551 / 2000$, os registros de patrimônios imateriais podem ser classificados em cinco categorias: Saberes - ofícios e modos de fazer (conhecimentos e modos de fazer enraizado no cotidiano das comunidades); Celebrações rituais e festas que marcam a vivência coletiva do trabalho, da religiosidade, do entretenimento e de outras práticas da vida social; Formas de expressão - manifestações literárias, musicais, plásticas, cênicas e lúdicas; Lugares: mercados, feiras, santuários, praças e demais espaços onde se concentram e reproduzem práticas culturais coletivas; e Edificações.

De acordo com o IPHAN (2018), até o final do ano de 2017 foram registrados 41 patrimônios imateriais distribuídos pelos estados do Brasil e Distrito Federal. Ressalte-se que os únicos bens culturais de abrangência nacional classificados foram: a Roda de Capoeira (formas de expressão) e o Ofício dos Mestres de Capoeira (saberes).

Já o registro de bens culturais de natureza imaterial do estado de Alagoas segue as prescrições da Lei Estadual $n^{\circ} 7.285 / 2011$, utiliza as mesmas categorias do referido Decreto 
federal para a inscrição de patrimônio e estabelece as diretrizes e instruções técnicas para solicitação dos registros pela Secretaria Estadual de Turismo.

Antes mesmo da promulgação da Lei Estadual, esforços haviam sido realizados no sentido de reunir informações sobre as referências culturais imateriais mais expressivas, com destaque para o projeto intitulado "Mapeamento do Patrimônio Cultural Imaterial de Alagoas", executado por equipe multidisciplinar da Universidade Federal de alagoas, em parceria com o Iphan. Tal projeto teve por objetivo organizar e fornecer um amplo conjunto de referências com vistas a valorização, preservação e disseminação do patrimônio cultural imaterial do estado. Com base na metodologia descrita pelo Inventário Nacional de Referência Culturais (INRC), foram catalogadas 539 referências, a partir de 466 fontes documentais encontradas em 70 municípios, e classificadas de acordo com o Quadro 2.

Quadro 2 - Referências do Patrimônio Cultural Imaterial de Alagoas

\begin{tabular}{|c|c|c|c|}
\hline SABERES & 240 & FORMAS DE EXPRESSÃO & 144 \\
\hline Práticas gastronômicas & 120 & $\begin{array}{l}\text { Folguedos (16 natalinos, } 9 \\
\text { carnavalescos e } 2 \text { religiosos) }\end{array}$ & 27 \\
\hline Atividade de pesca & 29 & Lendas & 25 \\
\hline Manualidades & 25 & Mitos, crendices e superstições & 9 \\
\hline Prática agrícola & 11 & Danças e cortejos & 23 \\
\hline Universo mágico-religioso & 10 & Brincadeiras & 18 \\
\hline Lúdicos & 5 & Cantos e cantigas & 13 \\
\hline \multirow[t]{5}{*}{ Criações de animais } & 4 & Contos, trovas, poesias e estórias & 11 \\
\hline & & Bandas e as músicas & 8 \\
\hline & & Representações teatrais & 4 \\
\hline & & Torneios & 3 \\
\hline & & Cultos religiosos & 3 \\
\hline CELEBRAÇÕES & 100 & LUGARES & 67 \\
\hline Celebrações de natureza religiosa & 46 & & \\
\hline Comemorações católicas & 37 & EDIFICAÇÕES & 24 \\
\hline Festividades profanas & 5 & & \\
\hline $\begin{array}{c}\text { Festividades ligadas às populações } \\
\text { indígenas }\end{array}$ & 5 & & \\
\hline Universos religiosos afro-brasileiros & 4 & & \\
\hline $\begin{array}{c}\text { Celebrações associadas às atividades } \\
\text { agrícolas }\end{array}$ & 3 & & \\
\hline
\end{tabular}

Fonte: Elaborado pelas autoras - Adaptado do IPHAN/UFAL/FUNDEPES, 2008.

Pelo exposto no Quadro 2, é significativa a diversidade de bens imateriais, o que evidencia a riqueza do patrimônio cultural alagoano. Destaca-se o volume de referências relacionado a ofícios e modos de fazer (Saberes), sendo as práticas gastronômicas um dos pontos fortes. Existe uma ampla variedade na culinária alagoana decorrente da riqueza das 
lagoas costeiras. A culinária típica no estado é composta por frutos do mar, peixes e camarões. O Sururu de Capote é um dos mais tradicionais, além de outros pratos, como a feijoada, as carnes de bode e carneiro (como a buchada), tapioca, cuscuz de milho, massa puba, pamonha, munguzá, canjica, pé-de-moloque e a macaxeira com carne de sol. Outra manifestação cultural importante é o artesanato (trabalhos em rendas e bordados, palha, madeira e cerâmica) no qual alguns municípios possuem núcleos de produção, sendo a tecelagem o gênero artesanal de maior destaque transmitido por gerações.

No que diz respeito a localização dos bens imateriais, apesar da abordagem territorial superar a concepção de escalas subnacionais, foi utilizado na pesquisa o recorte municipal.

A Categoria Ofícios e modos de fazer estão concentradas nos municípios de Piranhas, Penedo, Maceió, Porto Real do Colégio, Girau do Ponciano, Palmeira dos Índios, Viçosa, São José da Laje, Marechal Deodoro, Rio Largo, Delmiro Gouveia, Água Branca, Santana do Ipanema, Igreja Nova, São Brás, Traipú, São Sebastião, Arapiraca, Igaci, Quebrangulo, Mar Vermelho, Taquarana, Belém, Anadia e Passo de Camaragibe.

\section{Figura 1 - Ofícios e modos de fazer}

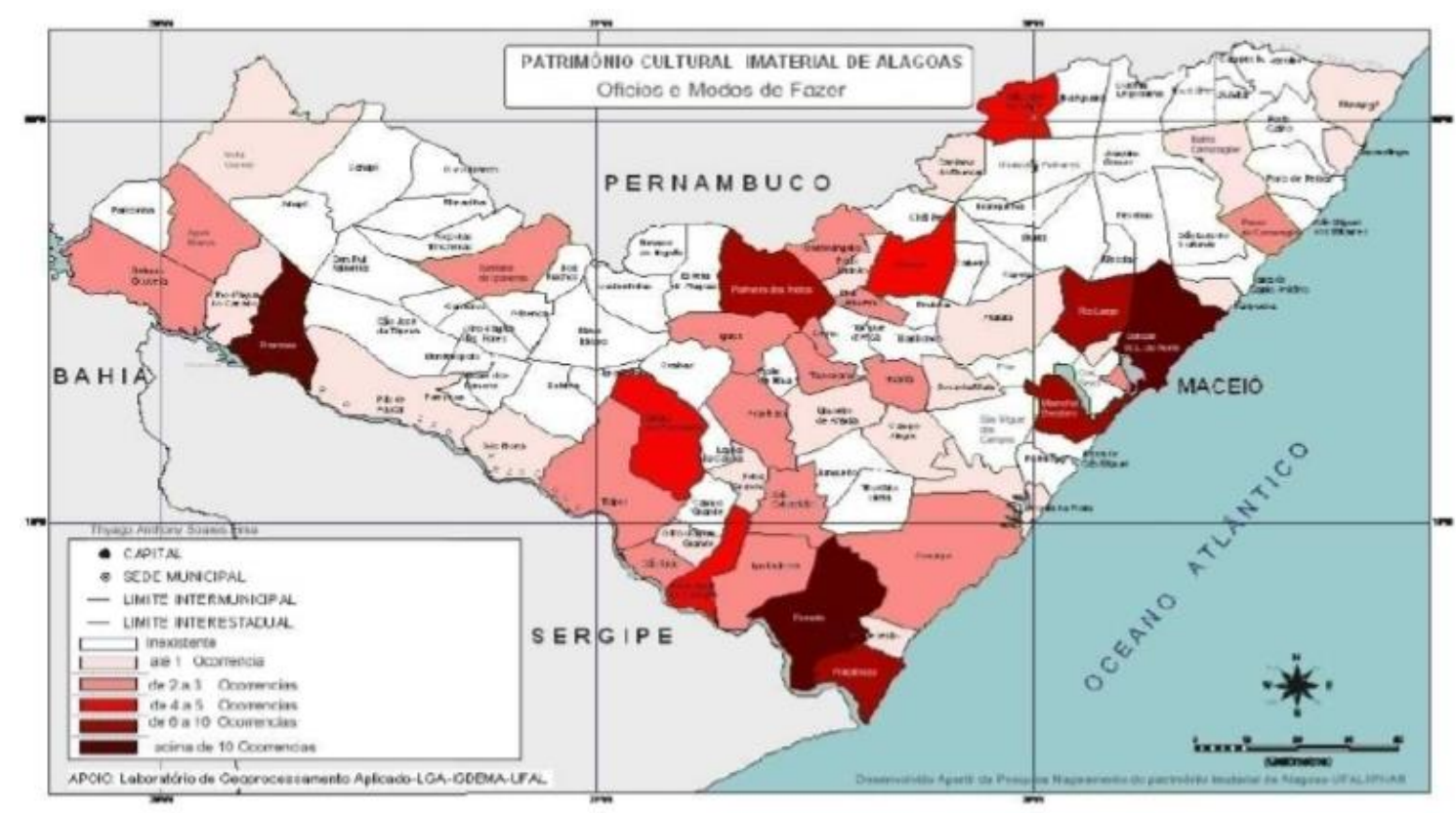

Fonte: Extraído de IPHAN/UFAL/FUNDEPES, 2008.

Todavia as ocorrências da categoria Formas de expressão estão localizadas em Penedo, Coruripe, Maceió, Marechal Deodoro, Pilar, Viçosa, Palmeira dos Índios, Quebrangulo, Piaçabuçu, Porto Real do Colégio, Mata Grande, Piranhas, Pão de Açúcar, 
Anadia, Cajueiro, Capela, Murici, União dos Palmares, São Luiz do Quitunde, Barra de Santo Antônio, Paripueira, Passo de Camaragibe, Matriz do Camaragibe, Porto de Pedras, Porto Calvo, Maragogi, Japaratinga, Maravilha, Poço das Trincheiras, São José da Tapera, Palestina, Santana do Ipanema, Batalha, Traipú, Arapiraca, Junqueiro, São Sebastião, Igreja Nova, Campo Alegre, São Miguel dos Campos, Coqueiro Seco, Atalaia e Maribondo.

\section{Figura 2 - Formas de expressões}

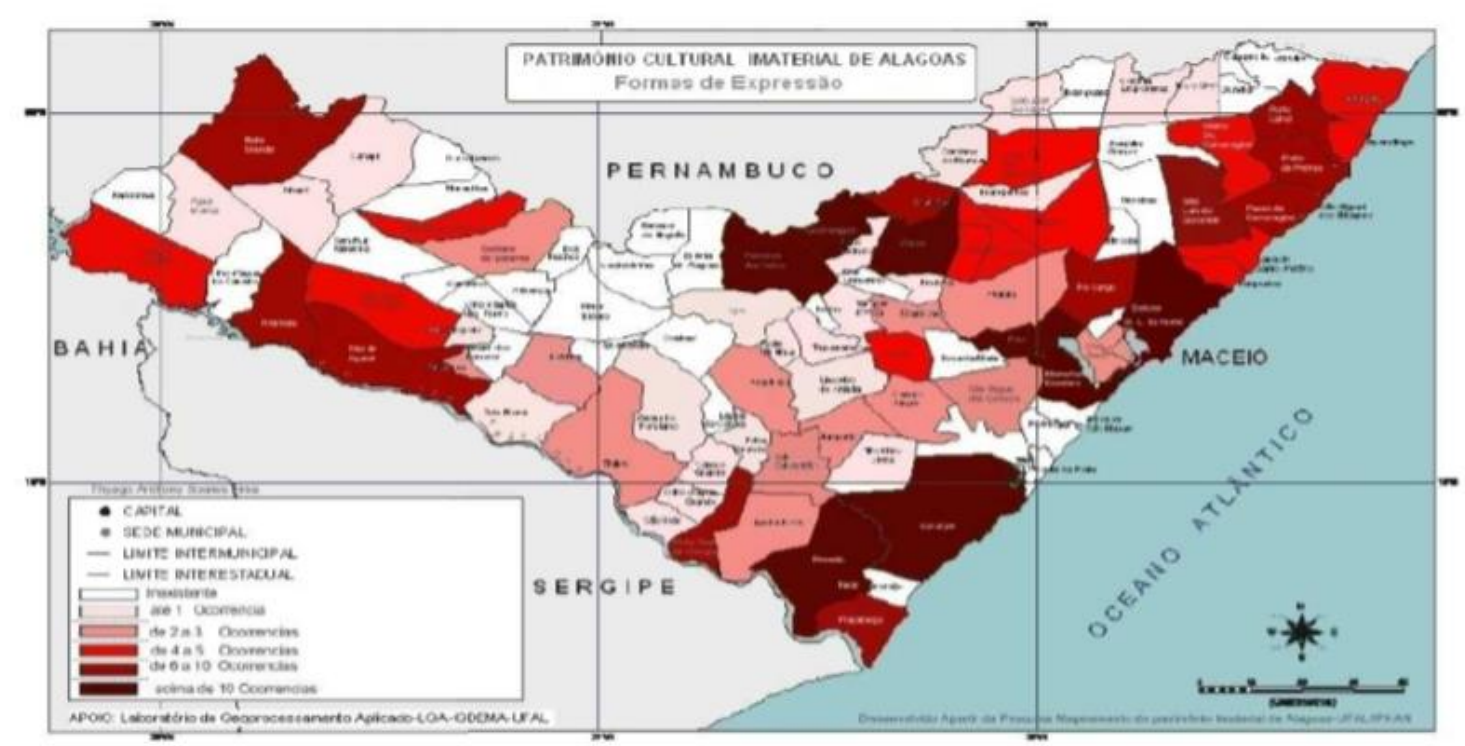

Fonte: Extraído de IPHAN/UFAL/FUNDEPES, 2008.

No tocante a categoria Lugares, essas apresentam maiores ocorrências na capital do estado, Maceió, em União dos Palmares, Porto Calvo, Coqueiro Seco, Santa Luzia do Norte, Pilar, Atalaia, Viçosa, Palmeira dos Índios, Arapiraca, Porto Real do Colégio e Piaçabuçu. Já no que se refere a categoria Celebrações, as ocorrências são mais frequentes em Maceió, Marechal Deodoro, Palmeira dos Índios, São José da Laje, Passo de Camaragibe, Matriz do Camaragibe, Penedo e Coruripe. No entanto a categoria Edificações apresentam um maior número de ocorrências em Maceió, Passo de Camaragibe, Marechal Deodoro, Palmeira dos Índios, Penedo e Santana do Ipanema.

Deve-se destacar que especialmente os saberes e as formas de expressão além de revelar as influências étnicas, também estão associadas as formas de ocupação e povoamento do território alagoano, bem como as expressões quilombolas, a atividade açucareira e a pesca 
artesanal. Apesar do expressivo conjunto de referências culturais pesquisadas e catalogadas pelo "Mapeamento do Patrimônio Cultural Imaterial de Alagoas" (projeto este reconhecido, financiado e recomendado pelo próprio Iphan), em todo o estado constam apenas cinco registros de bens imateriais junto à SECULT, conforme apresentado no Quadro 3.

Quadro 3 - Bens Imateriais de Alagoas registrados pela SECULT

\begin{tabular}{|l|l|}
\hline \multicolumn{2}{|c|}{ SABERES (OFÍCIOS E MODOS DE FAZER) } \\
\hline \multirow{2}{*}{ Prática gastronômica } & Camarão Alagoano - Bar das Ostras \\
\cline { 2 - 2 } & Doce de Caju de Ipioca \\
\hline \multirow{2}{*}{ Manualidades } & Bico e Renda Singeleza \\
\cline { 2 - 2 } & Filé \\
\hline Atividade de pesca & Sururu \\
& \\
\hline
\end{tabular}

Fonte: Elaboração das autoras, com base nos registros da SECULT, 2018.

O primeiro bem registrado no estado foi a receita do "Camarão Alagoano - Bar das Ostras", através da resolução do Conselho Estadual de Cultura de 9 de abril de 2013. De acordo com a SECULT, o registro como Patrimônio Cultural Imaterial de Alagoas teve por finalidade reconhecer os padrões culturais, os saberes, a história e a memória relacionadas à tradição da gastronomia alagoana, intimamente ligada ao ecossistema das lagoas, as técnicas de manuseio e tratamento de pescados e crustáceos, a produção artesanal de ingredientes (manteiga, dentre outros). O registro está baseado nas descrições históricas que demonstram que o Bar das Ostras é uma referência gastronômica, no qual durante o período de 1950 a 2002 foi ponto de encontro da elite política e intelectual de Alagoas.

O segundo reconhecimento e registro de patrimônio foi o "Doce de Caju de Ipioca" também no ano de 2013, no mês de dezembro. Este consiste no produto final de uma vasta rede de relações da cultura imaterial particular do litoral alagoano. Desde os tempos da colonização os doces compõe a culinária alagoana, apesar de ser uma herança dos portugueses, no estado há o hábito de fazer doces, especialmente pela grande quantidade de frutas tropicais e do açúcar. Ipioca foi beneficiada com a forte cultura do açúcar, por meio dos engenhos, e do algodão, através das fábricas têxteis, visto que a dinâmica econômica do município dependia dessas. Com a queda na produção do açúcar e do algodão a população 
passou a dedicar-se a outras atividades, como a cultura do coco e a piscicultura. Devido à enorme quantidade de cajueiros na região, as mulheres desenvolveram o doce de caju artesanal que se tornou atração local e para os turistas.

O terceiro registro de patrimônio imaterial concedido no estado foi o do "Bico e Renda Singeleza", no ano de 2014 (Figura 3). Genuinamente alagoano, o registro deste ofício revela a valorização da ancestralidade e das tradições de um trabalho manual que fora praticamente extinto se não tivesse sido preservado e aprimorado por uma única artesã, dona Marinita que faleceu no ano de 2006 (SECULT, 2018). Como forma de resgatar e preservar esse saber, o Projeto (Re) Bordando o Bico e Renda Singeleza realizado em 2009, sob a coordenação da professora Josemary Omena Passos Ferrare e apoiado pela SECULT e FUNDEPES, consistiu na realização de oficinas para ensinar o modo de fazer do Bico e da Renda Singeleza a mulheres, rendeiras e bordadeiras do município de Marechal Deodoro.

\section{Figura 3 - Bico e Renda Singeleza}

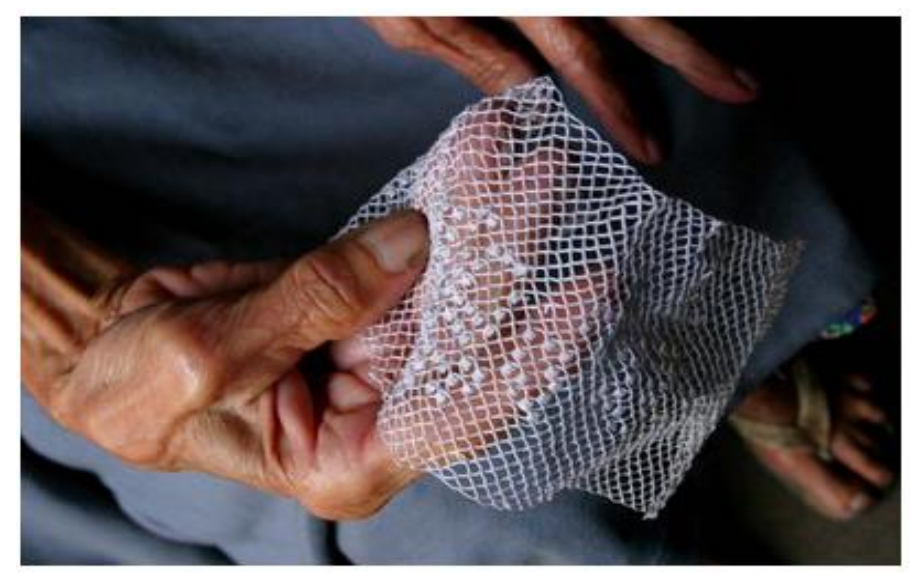

Fonte: Secretaria do Estado da Cultura (SECULT) - Autor: Ricardo Lêdo, 2018.

Ainda no ano de 2014, fora concedido o quarto registro ao "Bordado Filé" (Figura 4), três anos depois da solicitação realizada e assinada por sete cooperativas e associações de bordadeiras de Alagoas. 


\section{Figura 4 - Bordado Filé}

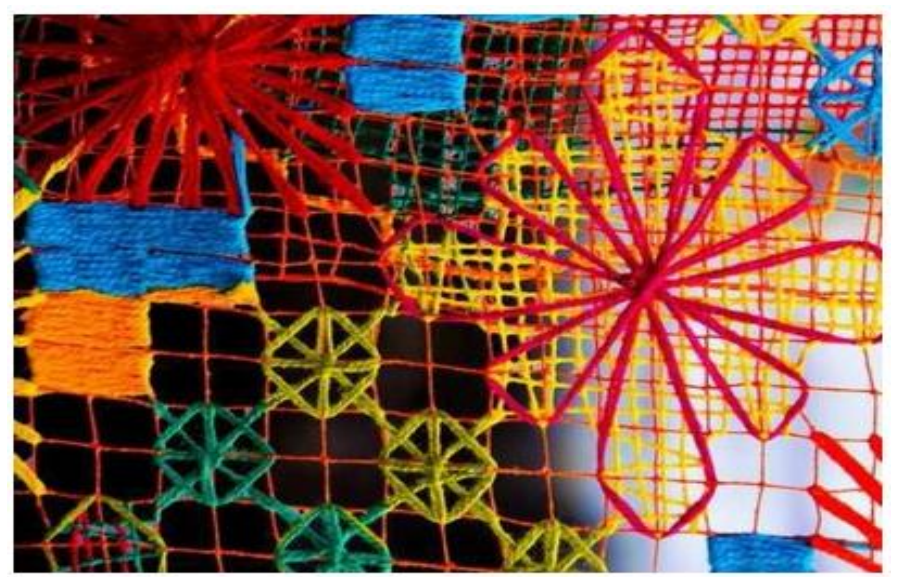

Fonte: Secretaria do Estado da Cultura (SECULT) - Autor: Jonathan Lins, 2018.

O Filé é um dos destaques do artesanato do estado e uma tradição típica do complexo estuarino Mundaú-Manguaba, estando seus grandes núcleos de produção situados na capital do estado, Maceió, especialmente nos bairros do Pontal da Barra e Riacho Doce e no município de Marechal Deodoro. O processo de produção do Filé originou-se da rede de pesca, consistindo em um trabalho de tecelagem manual. Não há certeza de quando o Filé chegou ao estado, porém é reconhecida a influência europeia, sendo seu conhecimento transmitido pelas mulheres portuguesas. Contudo, há distinções entre os produtos alagoanos e os confeccionados por outras comunidades que ainda conservam essa prática. O estilo é ímpar, tendo em vista a variedade e complexidade de execução dos pontos, bem como a intensidade de cores do bordado confeccionado neste território. Uma das principais organizações que buscam salvaguardar a tradição da região das Lagoas Mundaú e Manguaba é o Instituto do Bordado Filé através do fortalecimento do ofício, via promoção de divulgações turísticas e destacando seus diferenciais de qualidade em relação aos concorrentes.

O quinto e último registro de bem imaterial realizado em Alagoas foi o "Sururu de capote", no mês de dezembro, do ano de 2014 (Figura 5). Seu histórico consumo tornou-o um dos pratos típicos da culinária do estado, sendo esse retirado principalmente da lagoa Mundaú por meio de mergulho de um indivíduo ou grupo. 
Figura 5 - Sururu de capote

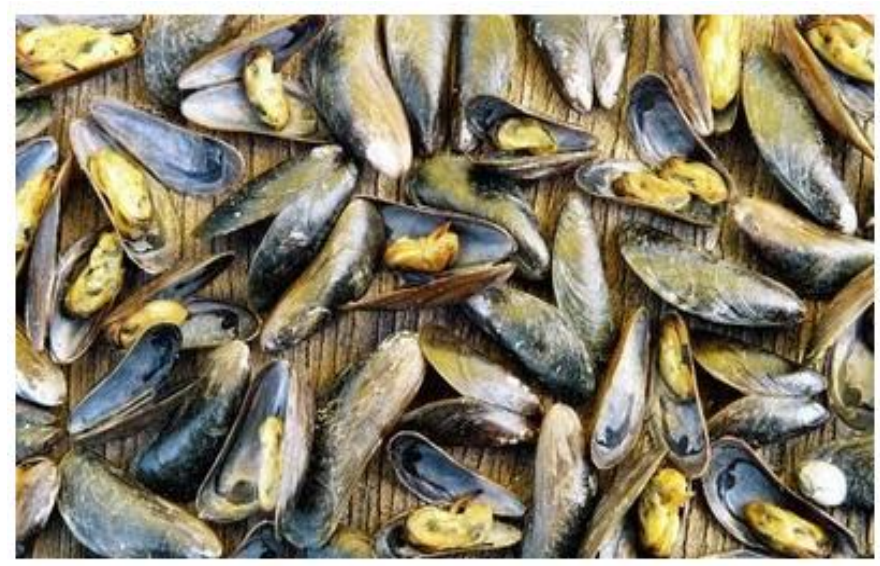

Fonte: Secretaria do Estado da Cultura - SECULT, 2018.

Esse molusco possui importância social, econômica, ambiental e cultural no estado, dadas suas utilidades gastronômicas, artesanais, filtradoras (purificação do ecossistema aquático), medicinais, entre outras. Especialmente contribui para a valorização da identidade de um povo e conservação de recursos necessários à formação cultural e econômica da região (LIMA, 2015). Segundo a SECULT, seu reconhecimento como patrimônio imaterial é significativo para a consagração da cadeia produtiva das culturas populares mestiças além de designar uma aproximação entre sociedade, natureza e história.

\section{Bens imateriais e indicações geográficas: recursos para o desenvolvimento territorial}

A Lei n ${ }^{\circ}$ 9.279/1996 define o marco legal das Indicações Geográficas (IGs) no Brasil que contempla dois aspectos: as Indicações de Procedência (IP) e as Denominações de Origem (DO). A IP faz referência ao nome geográfico de um país, cidade, região ou localidade de um território que "se tornou conhecido como centro de produção, fabricação ou extração de determinado produto ou prestação de determinado serviço" (INPI, 2018). Já a DO indica o nome geográfico de país, cidade, região ou localidade de seu território, que "designe produto ou serviço cujas qualidades ou características se devam exclusiva ou essencialmente ao meio geográfico, incluídos fatores naturais e humanos" (INPI, 2018).

Neste contexto, as IGs são instrumentos que favorecem a virtuosa associação entre as particularidades de procedência e origem do bem ou serviço (entendido aqui como ativo local) 
à qualidade e capacidade de diferenciação dos ativos presentes em um determinado território. Portanto, dada sua abrangência, não se trata de um único caminho de desenvolvimento, tendo em vista que as IGs viabilizam a salvaguardar e a reprodução de uma ampla gama de ativos locais que podem contribuir para diversificar e fortalecer os atores sociais e os sistemas produtivos. Outro aspecto, diz respeito aos estímulos à inovação através de uma nova forma de analisar e repensar o uso de recursos locais.

A inovação supõe, em muitos casos, resgatar saberes, práticas e/ou processos esquecidos, ao longo do tempo, por uma sociedade onde a padronização e uniformidade se impuseram de forma determinante, sobretudo na esfera agroalimentar. (ANJOS; CRIADO; CALDAS, 2013, p. 213)

No ano de 2012 foi registrada a primeira IG de Alagoas, a "Própolis Vermelha dos Manguezais", na espécie denominação de origem (DO). A IG foi um avanço importante para a apicultura de Alagoas, visto que foi a primeira denominação de origem do setor e a terceira do Brasil. Deste modo, o estado de Alagoas passou a ser reconhecido como o único produtor da Própolis Vermelha certificada a nível global.

Para Santa Rita et al. (2013) o selo da IG para Própolis Vermelha dos Manguezais de Alagoas foi uma estratégia, visto que permite ao estado ocupar espaços em mercados mais rígidos no que se refere a qualidade e reconhecimento de singularidade dos produtos.

O registro de Indicação geográfica $(\mathrm{IG})$, na espécie indicação de procedência, para o Bordado Filé da região das lagoas Mundaú-Manguaba foi concedido pelo Instituto Nacional da Propriedade Industrial (INPI) no ano de 2016. O território em questão abrange uma área de $252 \mathrm{~km}^{2}$ composta por parte dos municípios de Pilar, Marechal Deodoro, Santa Luzia do Norte, Coqueiro Seco, Satuba e Maceió com elevado potencial turístico. As comunidades em volta das lagoas Mundaú e Manguaba possuem historicamente o conhecimento sobre a produção do Filé. A IG foi concedida em nome do Instituto Bordado Filé das Lagoas de Mundaú-Manguaba (INIPI, 2016) e constitui-se em mais um instrumento de salvaguarda, bem como de garantia de qualidade, legitimidade, tradição e diferenciação de produto.

Essa é a única indicação geográfica existente no estado para patrimônio cultural. Ressalte-se a necessidade de se atribuir certificações de IGs a outros bens imateriais já identificados no estado, capazes de promover o desenvolvimento por meio do dinamismo dos aspectos particulares do território tais como outros artesanatos, expressões do folclore e tradições artísticas em geral. 


\section{Considerações finais}

Conforme visto, o enfoque territorial realça as particularidades históricas e culturais que inviabilizam regras únicas para consecução do desenvolvimento. Desta forma, é preciso valorizar as idiossincrasias do território, sobretudo os atores locais, de modo a permitir a manifestação de ativos específicos que possibilitem a criação de oportunidadas ao progresso.

A identificação, a valorização e o dinamismo da diversidade cultural brasileira, são processos importantes de reconhecimento e ativação das tradições. O patrimônio cultural imaterial de Alagoas, revelado pelos registros de inúmeras manisfestações de saberes, celebrações, formas de expressão, lugares e edificações, apresenta significância não só para preservação da memória e da identidade cultural do estado, bem como constitui uma coleção de recursos inéditos capazes de construir vias alternativas de desenvolvimento.

Duas possibilidades de ativação dos recursos patrimoniais foram apresentadas ao longo do trabalho: os registros dos bens imateriais e obtenção das indicações geográficas. Verificou-se que esses recursos ainda são pouco aproveitados no estado, representando elevado potencial de dinasmismo territorial. Acredita-se que mediante tais ações é possivel expressar elevada qualidade, diferenciação de produtos ou serviços, valorização de conhecimentos tradicionais e identidades culturais e potencializar os benefícios gerados pelo próprio sentido de pertencimento.

O grande desafio estará centrado, portanto, "na construção de cenários de desenvolvimento territorial a partir do local, tomando por base processos decisórios que transformem recursos específicos desses territórios em ativos a serviço desse desenvolvimento" (GUSMÃO, 2012, p.14)

\section{REFERÊNCIAS BIBLIOGRÁFICAS}

ABRAMOVAY, R. Agricultura familiar e desenvolvimento territorial. Revista da Associação Brasileira de Reforma Agrária, v. 28, nº 1,2 3 e 29, nº1, jan/dez 1998 e jan/ago 1999.

ALAGOAS. Lei $\mathbf{n}^{\mathbf{0}} \mathbf{7 . 2 8 5}$, de 30 de novembro de 2011. Disponível em:< http://www.cultura.al.gov.br/politicas-e-acoes/patrimonio-cultural/principal/legislacoes/leino-7.285-de-30-de-novembro-de-2011>. Acesso em: 28 ago. 2018.

. Secretaria de Estado da Cultura - SECULT. Cultura Alagoana. Disponível em: <https://www.estado-de-alagoas.com/cultura-alagoana.htm>. Acesso em: 28 ago. 2018.ALVES, E. P. M. Diversidade cultural, patrimônio cultural material e cultura popular: a Unesco e a construção de um universalismo global. Soc. estado. Brasília, v. 25, n. 3, p. 539-560, 2010 . Disponível 
http://www.scielo.br/scielo.php?script=sci_arttext\&pid=S0102-

69922010000300007\&lng=en\&nrm=iso>. Acesso em: 17 ago. 2018.

ANJOS, F. S.; CRIADO, E. A.; CALDAS, N. V. Indicações Geográficas e Desenvolvimento Territorial: Um Diálogo entre a Realidade Europeia e Brasileira. Revista Dados, Rio de Janeiro, v. 56, n.1, p. 207-236, Mar. 2013. Disponível em: < http://www.scielo.br/pdf/dados/v56n1/a09v56n1.pdf>. Acesso em: 10 set. 2018

BRASIL. Constituição Federal (1988). Disponível em:< http://portal.iphan.gov.br/uploads/legislacao/constituicao_federal_art_216.pdf >. Acesso em: 5 set. 2018.

Decreto $\mathbf{n}^{\mathbf{0}}$ 3.551, de 4 de Agosto de 2000. Institui o Registro de Bens Culturais de Natureza Imaterial que constituem patrimônio cultural brasileiro, cria o Programa Nacional do Patrimônio Imaterial e dá outras providências. Disponível em: $<$ http://www.planalto.gov.br/ccivil_03/decreto/D3551.htm>. Acesso em 5 set. 2018.

BONNAL, P.; CAZELlA, A. A.; DELGADO, N. G. Contribuições ao estudo do desenvolvimento territorial rural: reflexões metodológicas a partir do caso brasileiro. Biblio 3w (Barcelona), v. XVII, p. 1002, 2012.

FAVARETO, A. Retrato das políticas de desenvolvimento territorial no Brasil. Documento de Trabajo $N^{\circ}$ 26. Programa Dinâmicas Territoriales Rurales. Rimisp, Santiago, Chile, 2009.

FOLKE, C; BERKES, F. (Orgs.). Linking Social and Ecological Systems: Institutional Learning for Resilience, Cambridge: Cambridge University Press, 1998.

GUSMÃO, P. Elementos para a construção de uma agenda para a gestão ambiental da área de influência do porto de Itaguaí - RJ. In: Confins, v. 15, 2012.

INSTITUTO DO PATRIMÔNIO HISTÓRICO E ARTÍSTICO NACIONAL - IPHAN. Bens Registrados. Disponível em:<http://portal.iphan.gov.br/pagina/detalhes/606>. Acesso em: 20 ago. 2018.

. Mapeamento do Patrimônio Cultural Imaterial de Alagoas. Disponível em: < http://portal.iphan.gov.br/pagina/detalhes/959/>. Acesso em: 6 set. 2018.

IPHAN/UFAL/FUNDEPES. Mapeamento do Patrimônio Cultural Imaterial de Alagoas. Relatório Final, 2008. Disponível em: <http://portal.iphan.gov.br/uploads/ckfinder/arquivos/Relatorio_final_mapeamento_alagoas_ PNPI(1).pdf $>$. Acesso em: 6 set. 2018.

INSTITUTO NACIONAL DA PROPRIEDADE INDUSTRIAL - INPI. INPI concede indicação geográfica para bordado filé alagoano (2016). Disponível em: < http://www.inpi.gov.br/noticias/inpi-concede-indicacao-geografica-para-bordado-file-

alagoano>. Acesso em: 20 ago. 2018.

. Mapa das Indicações Geográficas brasileiras de 2017 é lançado. Disponível em: < http://www.inpi.gov.br/noticias/mapa-das-igs-brasileiras-de-2017-e-lancado. Acesso em: 09 set. 2018.

LIMA, M.C. A importância sócio-econômica, cultural e ambiental do sururu (mytella charruana) na terra de Alagoas: como se valorar esse recurso à luz de princípios da economia ecológica? Revista Incelências, v. 4. n.1, 2015.

PECQUER, B. O desenvolvimento territorial: uma abordagem dos processos de desenvolvimento para as economias do Sul. In: Raízes, v. 24, n. 1e 2, jan-dez, 2005, p. 1022. (Traduzido por Ghislaine Duque). 
PECQUEUR, B. Qualite et développement - L'hypothese du panier de biens. In: Symposium sur le développement regional. INRA-DADP. Montpellier, 2000.

RAFFESTIN, Claude. Por uma geografia do poder. Tradução de Maria Cecília França. São Paulo: Ática, 1993.

SANTOS, M. Território, Globalização e Fragmentação. São Paulo: Hucitec, 1994.

SANTA RITA, L. P. et al. Indicação geográfica da Própolis Vermelha de Alagoas: antecedentes e apropriabilidade em um sistema setorial de inovação. Disponível em: < http://www.altec2013.org/programme_pdf/127.pdf>. Acesso em: 20 Ago. 2018.

VIEIRA, P. F. Políticas ambientais no Brasil: do preservacionismo ao desenvolvimento territorial sustentável. Rev. Política \& Sociedade, Florianópolis, v. 8, n. 14, p. 27-75, 2009.

Recebido em 11 de setembro de 2018.

Aceito em 25 de outubro de 2018. 